\title{
Decolonialidade e Ciência da Informação: veredas dialógicas
}

\author{
Decoloniality and Information Science: Dialogical \\ pathways
}

\author{
Andre Vieira de Freitas Araujo a,* (ib \\ Lucia Maciel Barbosa de Oliveira b \\ Luciana Gracioso ${ }^{\circ}$ (I) \\ Marco Donizete Paulino da Silva c (D)
}

A temática da Decolonialidade emerge dos tensionamentos e das fissuras da contemporaneidade. Suas possibilidades e suas condições de desenvolvimento em relação à Informação e à Cultura são elementos determinantes tanto de uma ordem teórica quanto metodológica para o planejamento de ações e movimentos que visam a inclusão e a equidade.

Assumir que o conhecimento é elemento determinante para a manutenção ou contestação da hegemonia, portanto, um universo em disputa, significa transpassar o conhecimento legitimado a partir de outras epistemologias. Decolonizar o saber é ação fundamental para a decolonização do próprio poder, na medida em que as relações de colonialidade não acabaram com o fim do colonialismo. Há múltiplas formas de conceber o mundo, de conhecê-lo, de criá-lo, de nele estar, formas que foram sistematicamente obscurecidas. Como tais questões estão alcançando, rebatendo, rasurando a Ciência da Informação, como campo de conhecimento forjado a partir da colonialidade?

\footnotetext{
a Universidade Federal do Rio de Janeiro, Rio de Janeiro, RJ, Brasil.

b Universidade de São Paulo, São Paulo, SP, Brasil.

c Universidade Federal de São Carlos, São Carlos, SP, Brasil.

* Correspondência paral Correspondence to: Andre Vieira de Freitas Araujo. E-mail: armarius.araujo@gmail.com.

Artigo publicado em acesso aberto sob licença CC BY 4.0 Internacional @(i)
} 
Sob este horizonte, concebemos o encontro "Decolonialidade e Ciência da Informação: veredas dialógicas"” cujo objetivo foi promover aproximações dialógicas entre a temática da Decolonialidade e o campo da Ciência da Informação, além de contribuir para com o compartilhamento de pesquisas críticas do campo informacional. $\mathrm{O}$ encontro ${ }^{2}$ pretendeu identificar as possíveis contribuições entre campos disciplinares diversos e diagnosticar caminhos de condução de uma construção epistemológica tão rica quanto inclusiva e diversificada de saberes e identidades sociais, observando níveis de desenvolvimento de conhecimentos

\footnotetext{
1 O encontro "Decolonialidade e Ciência da Informação: veredas dialógicas" foi realizado nos dias 01 e 02 de outubro de 2020 e organizado pelo Departamento de Biblioteconomia da Universidade Federal do Rio de Janeiro (DB-UFRJ), Programa de Pós-Graduação em Ciência da Informação da Escola de Comunicações e Artes da Universidade de São Paulo (PPGCI-ECA-USP), Programa de Pós-Graduação em Ciência da Informação da Universidade Federal de São Carlos (PPGCI-UFSCar) e Programa de Pós-Graduação em Ciência, Tecnologia e Sociedade da Universidade Federal de São Carlos (PPGCTS-UFSCar). O encontro foi constituído por: Painel Escritos e Escritores Decoloniais, Plataformas Virtuais para Pensar, 3 sessões de palestras, 1 conferência, além da presença de provocadores externos ao campo da Ciência da Informação. A programação completa do evento pode ser acessada aqui $<$ https://www.dci.ufscar.br/events/encontro-decolonialidade-e-ciencia-da-informacao-veredasdialogicas $>$. Já o acesso às sessões pode ser feito a partir do canal do encontro, no Youtube: <https://www.youtube.com/channel/UCDS9vTQ9pnFvYmein84kaWg/about>.
}

${ }^{2}$ Como um projeto efetivo e que depois tornou-se, de fato, um projeto afetivo, o encontro "Decolonialidade e Ciência da Informação: veredas dialógicas" resultou de um rico diálogo entre os seus organizadores; cada qual com percursos de ensino e pesquisas distintos, mas que se aproximaram e efetivamente se encontraram a partir das relações existentes entre Informação e Cultura. No contexto da USP, a partir da disciplina "Dinâmicas Culturais Contemporâneas" (PPGCI-ECA-USP), Lucia Maciel Barbosa de Oliveira e Andre Vieira de Freitas Araujo têm confrontado alguns dos temas que impulsionaram a proposição deste evento: diversidade (a partir Gustavo Lins Ribeiro), universalismo (a partir de Renato Ortiz), saberes tradicionais e científicos (a partir Manuela Cunha), terceiro espaço (a partir de Homi Bhabha), organização do conhecimento pela perspectiva pós-colonial (a partir de García Gutierrez), interseccionalidade em Organização do Conhecimento (a partir de Melodie Fox), decolonização de documentação etnográfica (a partir de Hannah Turner) e memória e patrimônio (a partir dos antimonumentos e a repatriação de bens culturais). Por outro lado, no contexto da UFSCar, Luciana de Souza Gracioso tem feito incursões sobre Decolonialidade, Epistemologias emancipatórias e Ciência da Informação Nativa. Gracioso tem pensado a Decolonialidade a partir da Linguagem e da Ação Comunicativa de Habermas, entendendo que, talvez, a esfera pública (mesmo que ela se realize apenas teoricamente) possa ser o ambiente necessário para uma ação decolonial genuína. Luciana Gracioso, pela via da Linguagem, e Marco Donizete Paulino da Silva, pela via da Interdisciplinaridade, projetaram, em 2020, um pequeno evento para contextualizar a discussão sobre a Decolonialidade e Ciência da Informação na UFSCar, mas que foi diretamente impactado pelo início da pandemia não sendo possível de ser realizado. Em continuidade a essas imbricações, tanto Gracioso quanto Silva depositaram interesse na perspectiva sistêmica como via de abordagem das relações de poder por meio de ações comunicativas de ordem estratégica e dramatúrgica (com resultados apresentados e publicados) compondo base de reflexão sobre a variedade de teorias que caberiam como possibilidades de investigação dos processos de interação em sistemas complexos - aporte inicial de uma exploração no nível de pós-doutorado em atual desenvolvimento. Este conjunto de percursos representam a base para a concepção do encontro e do dossiê "Decolonialidade e Ciência da Informação: veredas dialógicas". 
sistematizados e não sistematizados, assim como formas de torná-los tão acessíveis quanto protegidos da exploração predatória.

O encontro pôde constituir mais uma ação que tem estabelecido aproximações, em nosso país, entre a temática da Decolonialidade e a Ciência da Informação, considerando as recentes publicações de livros e artigos, produções de teses e dissertações, proposições de disciplinas no nível da graduação e pós-graduação e grupos formados no contexto associativo-informacional ${ }^{3} 4$ e/ou no contexto acadêmico 5 .

Nessas condições, o evento "Decolonialidade e Ciência da Informação: veredas dialógicas" se justificou pela qualidade interdisciplinar que o embate de proposições exige e propicia, considerando-se que a evolução de um conhecimento pleno e holístico, em uma ordem democrática, tem por compromisso contribuir para o delineamento de uma realidade também plena, e composta por diversos níveis de exteriorização de teorias, metodologias e agentes sociais e institucionais, em dois níveis de aplicação: em curto e médios prazos; e, em longos prazos.

O ponto de apoio dessa consideração se dá pela ideia de que não há como avançar na produção eficiente de um conhecimento mutuamente construtivo sem o diálogo interpelativo, e integrador, por meio de ações que viabilizem tanto o avanço de campos interrelacionados quanto da estrutura social, perpassada por realidades culturais e informacionais constante e dinamicamente interdependentes.

Como desdobramento do evento, o presente dossiê temático "Decolonialidade e Ciência da Informação: veredas dialógicas", abrigado pela Liinc em Revista, tem como horizonte tanto as questões teóricas quanto questões práticas do pensamento/fazer/saber decolonial relacionados ao campo informacional, além de experimentações artísticas, o que, potencialmente, expande as relações interdisciplinares e aprofunda as discussões decoloniais no contexto específico da Ciência da Informação.

\footnotetext{
3 Em julho de 2020 foi criado o "Grupo de Trabalho Relações Étnico-raciais e Decolonialidades" (RERAD), vinculado à Federação Brasileira de Associações de Bibliotecários, Cientistas da Informação e Instituições (FEBAB). Para informações sobre o Grupo, ver: $<$ https://www.acoesfebab.com/etnico .

4 Em julho de 2021 foi criado o "Grupo Especializado em Relações Étnico-Raciais em Biblioteconomia da Associação Catarinense de Bibliotecários" (GEREB - ACB/SC).

${ }^{5}$ Em outubro de 2021 foi aprovada a criação, durante o XXI Encontro Nacional de Pesquisa e Pós-Graduação em Ciência da Informação (ENANCIB), do "GT 12 - Informação, Estudos Étnicoraciais, Gênero e Diversidades" pela Associação Nacional de Pesquisa e Pós-Graduação em Ciência da Informação (ANCIB).

${ }^{6}$ Este dossiê contou com uma chamada aberta para publicações e possui contribuições tanto de sujeitos que participaram diretamente do evento quanto de sujeitos que fizeram as suas submissões a partir dessa proposição.
} 
O tema da Decolonialidade transpassa várias camadas e níveis de construção social do conhecimento, retendo em seu arcabouço noções sobre informação e saber, advindas da consciência gradativamente crescente sobre as questões de silenciamento e subjugação de povos, etnias, classes e gêneros, ou, identidades de grupo que compõem um mosaico sócio-tecnológico que entrelaça toda história humana.

Edgard Lander (2005) refere-se à colonialidade do saber como legado epistemológico que nos impede de compreender o mundo a partir do próprio mundo em que vivemos e das epistemes que lhe são próprias, da multiplicidade que as constituem. Sílvia Cusicanqui (2018) constrói a ideia da epistemologia como ética, como uma autoconstrução a partir do diálogo. Uma ética que se transforma em estética, um pensar em comum que é também um fazer em comum.

Nessa perspectiva, as discussões acerca das abordagens e dos interesses de pesquisa - direcionadas, ou não, por um caráter disciplinar, ou de monopólio de um dado campo de conhecimento - tornam-se tópicos necessários para se entender em que pontos as convergências e divergências epistemologicamente territorializadas acolhem ou disseminam realidades multifocais, com possibilidades de discordâncias ou concordâncias mutuamente enriquecedoras.

Se de um ponto de vista especializado os subtemas relacionados a olhares culturais multifacetados se distanciam do horizonte ideal, como um recorte da realidade objetiva, cada vez mais, percebe-se a urgência na consideração de uma perspectiva holística em que recortes multivariados, ainda que atritantes, ou simplesmente, refratários entre si, sejam considerados relevantes na construção de uma vereda em que o humano, o social, o tecnológico, o científico, o artístico, o político, tornem-se parte integrante das discussões ampliadas, mesclando noções objetivas sobre os discursos e as estratégias subjetivas variadas, ambas contribuintes para o desenvolvimento do conhecimento como um todo.

Alicerçado nas considerações precedentes, este dossiê da Liinc em Revista convocou pesquisadoras e pesquisadores da Ciência da Informação e áreas afins a apresentarem resultados de pesquisa teórica, aplicada e experimentais sobre os tópicos relacionados ao temário do Dossiê, nas seguintes vertentes:

- Estudos decoloniais da informação, da documentação e da comunicação

- Identidades e pós-identidades

- Perspectivas decoloniais da produção e comunicação científica

- Pluriepistemologias, ecologia dos saberes e epistemicídios

- Poéticas decoloniais: arte, estética e literatura

- Tecnologias e cosmotecnologias

- Tempo e memória 
Sob a temática dos "Estudos decoloniais da informação, da documentação e da comunicação" contamos com as contribuições "Competência em informação como forma de pedagogia decolonial e intercultural: construindo significados", de Guilherme Goulart Righetto, Cezar Karpinski e Elizete Vieira Vitorino; "Colonialidade, classificação e poder", de Mariana Rodrigues Gomes de Mello e Daniel Martínez-Ávila; "Da representação à perspectivação de(s)colonial do conhecimento: a ontologia informacional sob a tez ameríndia", de Vinícios Souza de Menezes; "Dorothy Porter Wesley e a Organização do Conhecimento Negro na Coleção Especial MoorlandSpingarn Research Center", de Franciéle Carneiro Garcês da Silva, Dirnéle Carneiro Garcez, Rodrigo de Sales e Gustavo Silva Saldanha; "Cartografias Subalternas: travessias epistemológicas para a Ciência da Informação", de Jéssica Paola Macedo Müller e Rodrigo Silva Caxias de Sousa; "Bibliotecología para América Latina y el Caribe, propuesta teórica y filosófica para la discusión", de Natalia Duque-Cardona e María Camila Restrepo-Fernández; "Veredas Dialogicas da Mediação: decolonialidade em Ciência da Informação", de Rubens Alves Silva e Luis Carlos Flecha e "Racismo estrutural, epistemologia da ignorância e a produtividade do discurso colonial: impactos na manutenção do acervo bibliográfico da Fundação Cultural Palmares", de Maria Aparecida Moura.

Na temática "Identidades e pós-identidades" temos os artigos "Para além da descrição da diferença: apontamentos sobre o método da roleta interseccional para estudos em Comunicação", de Fernanda Carrera e "Formação de professores indígenas e possibilidades decoloniais", de Ailton Salgado Rosendo e Heitor Queiroz de Medeiros.

Nas "Perspectivas decoloniais da produção e comunicação científica" encontramos as pesquisas "Ciência, informação e política na pandemia brasileira", de Maíra Baumgarten e Maria Helena Weber e "Publicación científica em acceso abierto: desafíos decoloniales para América Latina", de Nancy Sanchez Tarrago.

Em relação à temática "Pluriepistemologias, ecologia dos saberes e epistemicídios" temos a contribuição "O que é epistemicídio? Uma introdução ao conceito para a área da Ciência da Informação", de Robson de Andrade Gonçalves e Marcos Luiz Mucheroni.

No plano do tema "Poéticas decoloniais: arte, estética e literatura", o dossiê nos traz a pesquisa "A Evolução da Presença Negra na Mauricio de Sousa Produções: o reflexo do pensamento decolonial nos quadrinhos nacionais", de Rodrigo Sérgio Ferreira de Paiva, Breno José Andrade de Carvalho, Dario Brito Rocha Júnior, Fernanda Paiva Furtado da Silveira, Ana Luisa Erthal, Luciana Coutinho Araújo e Isabela Regina da Silva Pontes.

Sob a temática "Tecnologias e cosmotecnologias" temos o artigo "MostrEmCasa: Arte, Tecnologia e Experiência Decolonial no Contexto de Pandemia", de Claudio Xavier, Katia Santos de Morais e Nadia Virginia Barbosa Carneiro.

No âmbito do tema "Tempo e Memória", o dossiê traz as pesquisas "Afrocentricidade, Memória e Informação", de Camila Sá e Marivalde Francelin e "Entre coleções e 
monumentos coloniais: uma abordagem a partir do conceito de "patrimônio dissonante", de Giulia Crippa.

Além dos artigos, integram este número os seguintes relatos de experiência: "O textoperformance como tentativa de exuzilhamento", de Naiene Sanchez Silva e Thais Pereira da Silva; "Ciência da Informação: racionalidade, corporeidade e outras perspectivas de conhecer e informar", de Selma Cristina da Silva; "Cultura, Conhecimento e Memória: olhares decoloniais", de Naiene Sanchez e Selma Cristina da Silva; "O índio escritor será que existe?", de Olívio Jekupé e "Conjunção de conteúdos do projeto Células Cênicas com o ambiente Plataforma Virtual para Pensar, no contexto do I Encontro Decolonialidade e Ciência da Informação: Veredas Dialógicas", de Marco Donizete Paulino da Silva e Nádia Regina Stevanato.

Cayo Honorato e Suene Honorato assinam o artigo de opinião "Interseccionalidade e encruzilhada: exuzilhamentos".

Encerram o dossiê dois ensaios visuais, "Desmontagem Ascendente", de Rodrigo de Araujo, e "Memória Ancestral", de Laíza Ferreira, e a resenha "Desconstruindo mitos de origem: a língua portuguesa é um fenómeno tardio que vem do galego e não de fenícios ou de árabes", de Vítor de Sousa.

Essas contribuições, tomadas em conjunto, evocam a ideia de encontro que tanto nos acompanhou na concepção do evento quanto na organização deste dossiê.

A propósito da ideia de encontro, em sua fala na abertura da Mostra Internacional de Teatro - MIT, realizada em março de 2020 (dias antes da decretação do isolamento em virtude da pandemia), Ailton Krenak formulou uma reflexão instigante:

\footnotetext{
Nós adiamos o fim de cada mundo, a cada dia, exatamente criando um desejo de verdade de nos encontrarmos amanhã, no final do dia, no ano que vem. Esses mundos encapsulados uns nos outros que nos desafiam a pensar um possível encontro das nossas existências - é um desafio maravilhoso. (KRENAK, 2020, p. 8).
}

O dossiê "Decolonialidade e Ciência da Informação: veredas dialógicas" representa, por um lado, o registro dialógico sobre uma temática que a Ciência da Informação está esboçando e, de outro, uma vereda incontornável para o desenvolvimento desse campo no contexto brasileiro e latino-americano.

\section{REFERÊNCIAS}

CUSICANQUI, S. R. Un mundo ch'ixi es posible: ensayos desde un presente en crisis. Buenos Aires: Tinta Limón, 2018.

KRENAK, A. Do tempo. N-1edições. 2020. Disponível em: https://pospsi.com.br/wpcontent/uploads/2020/09/TEXTOS_38-ailton-krenak.pdf. Acesso em: 09 nov. 2021. 
LANDER, E. (org). A colonialidade do saber: eurocentrismo e ciências sociais: perspectivas latino-americanas. Buenos Aires: CLACSO, 2005. Disponivel em: https://ufrb.edu.br/educacaodocampocfp/images/Edgardo-Lander-org-AColonialidade-do-Saber-eurocentrismo-e-ciC3AAncias-sociais-perspectivaslatinoamericanas-LIVRO.pdf . Acesso em: 9 nov. 2021. 